\title{
Antibodies induced with recombinant VP1 from human rhinovirus exhibit
} cross-neutralisation

\author{
J. Edlmayr*,§, K. Niespodziana*,§, T. Popow-Kraupp\#", V. Krzyzanek", \\ M. Focke-Tejkl*, D. Blaas ${ }^{+}$, M. Grote and R. Valenta*
}

ABSTRACT: Human rhinoviruses (HRVs) are the major cause of the common cold and account for $30-50 \%$ of all acute respiratory illnesses. Although HRV infections are usually harmless and invade only the upper respiratory tract, several studies demonstrate that HRV is involved in the exacerbation of asthma.

VP1 is one of the surface-exposed proteins of the viral capsid that is important for the binding of rhinoviruses to the corresponding receptors on human cells. Here we investigated its potential usefulness for vaccination against the common cold.

We expressed VP1 proteins from two distantly related HRV strains, HRV89 and HRV14, in Escherichia coli. Mice and rabbits were immunised with the purified recombinant proteins.

The induced antibodies reacted with natural VP1 and with whole virus particles as shown by immunoblotting and immunogold electron microscopy. They exhibited strong cross-neutralising activity for different HRV strains. Therefore, recombinant VP1 may be considered a candidate HRV vaccine to prevent HRV-induced asthma exacerbations.

KEYWORDS: Asthma, common cold, rhinovirus, vaccine

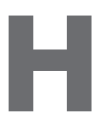
uman rhinoviruses (HRVs), generally known as the primary cause of acute upper respiratory infections, have recently emerged as important triggers for exacerbations of asthma, chronic obstructive pulmonary disease (COPD) and cystic fibrosis [1-5]. Furthermore, the pathogenic role of HRVs in lower respiratory tract infections of infants, elderly and immunocompromised patients has been reported [6-8].

HRVs are non-enveloped, single-stranded RNA viruses that belong to the Picornaviridae family [9, 10]. Currently, $>100$ distinct serotypes are primarily assigned to two genetic species, HRV-A and HRV-B, with $>70 \%$ amino acid identity and a similar antiviral susceptibility pattern within each species [11]. Recently, a third clade, HRV-C, including a number of previously unrecognised non-cultivable HRVs has been identified [12, 13]. In addition, the serotypes have also been classified into major and minor groups according to the receptor they use to enter epithelial cells of the respiratory tract. Members of the major receptor group bind to the intercellular adhesion

For editorial comments see pages 3 and 5 .

\section{AFFILIATIONS}

*Division of Immunopathology, Dept of Pathophysiology, Center of Pathophysiology, Infectiology and Immunology,

\# Institute of Virology, Medical University of Vienna, and

${ }^{+}$Max F. Perutz Laboratories, Dept of Medical Biochemistry, Medical

University of Vienna, Vienna, Austria. -Institute of Medical Physics and Biophysics, University of Muenster, Muenster, Germany.

${ }^{\S}$ Both authors contributed equally to the work.

CORRESPONDENCE

R. Valenta

Division of Immunopathology

Dept of Pathophysiology

Center of Pathophysiology,

Infectiology and Immunology

Medical University of Vienna AKH Ebene 30

Waehringer Guertel 18-20

1090 Vienna

Austria

E-mail: rudolf.valenta@

meduniwien.ac.at for the antigenic diversity of HRV, whereas the fourth, VP4, is located inside the virion [17, 18]. Of the four viral capsid proteins, VP1 is the most exposed and immunodominant surface protein. It is critically involved in the infection of respiratory cells and is predominantly recognised by HRV neutralising antibodies [19-23].

The ability to identify rhinoviruses using highly sensitive and specific PCR-based technology has dramatically increased the frequency of HRV detection and has provided the basis for several studies indicating the involvement of HRVs in triggering asthma [1, 2, 24-27]. HRVs have been found to be the most frequent pathogen present in $50-80 \%$ of asthma exacerbations in both children and adults, with peak levels in spring and autumn when rhinovirus infections usually
Received:

Sept 212009

Accepted after revision:

May 262010

First published online:

June 072010 
occur [24, 25]. Furthermore, rhinovirus infections during infancy are the most significant risk factors for the subsequent development of asthma [26]. Finally, rhinoviruses may also contribute to the persistence and severity of the disease when they are present in the lower airway $[2,28]$.

Several avenues have been followed towards the development of preventive and therapeutic strategies against rhinovirus infections [18, 29-32]. However, due to the occurrence of $>100$ HRV serotypes with high sequence variability in the antigenic sites [10], no rhinovirus vaccine and no HRV-specific drug has become available.

In this study we have expressed, in Escherichia. coli, VP1 proteins from two very distantly related HRV strains, HRV89 and HRV14, belonging to genus A and B, respectively, and studied whether their recombinant VP1 proteins can be used to induce cross-protective antibody responses in mice and rabbits.

\section{MATERIALS AND METHODS}

\section{Construction of expression vectors harbouring the VP1 cDNA of HRV14 or HRV89}

The plasmid containing the whole genome of HRV14 [33] was used as a template for the amplification of 14VP1 (VP1 of HRV14) by PCR. The following primers were used: 5' CGGAATTCCCATGGGCTTAGGTGATGAATTAGAAGAAG TCATCGTTGAGA 3'; and 5' GATGGAATTCTCAGTGGTG GTGGTGGTGGTGATAGGATTTAAT $\overline{\text { GTCAC }}{ }^{\prime}$.

The restriction sites (NcoI and EcoRI) are underlined. The cDNA coding for the 14VP1 region (database no. AY355195) was inserted into the NcoI and EcoRI sites of plasmid pET23d (Novagen; Merck Bioscience, Darmstadt, Germany). Virus stocks of HRV89 were obtained from the collection of the Institute of Virology, Medical University of Vienna, Vienna, Austria. Viral RNA was prepared from cell culture supernatants using the QIAamp viral RNA kit (Qiagen, Hilden, Germany) and RNase inhibitor (Boehringer Ingelheim $\mathrm{GmbH}$, Ingelheim, Germany) was added to a final concentration of $0.01 \mathrm{U} \cdot \mu \mathrm{L}^{-1}$. The 89VP1 cDNA (VP1 of HRV89) was amplified by RT-PCR using the SuperScript One Step RT PCR Kit from Invitrogen (Carlsbad, CA, USA) using the following primers: 5' CGGAATTCATTAATATGAACCCAGTTGAAAATTATATA GATAGTGTATTA 3'; and 5' CGATTAATTCAGTGGTGGTG GTGGTGGTGGACGTTTGTAACG $\overline{\text { GTAA } 3^{\prime}}$.

The restriction sites (EcoRI and AseI) are underlined. The cDNA encoding the complete 89VP1 region (database no. AY355270) was subcloned into the NdeI and EcoRI site of pET17b (Novagen; Merck Bioscience).

\section{Expression and purification of recombinant 89VP1 and 14VP1}

Recombinant 89VP1 and 14VP1 were expressed in E. coli BL21(DE3) (Stratagene, La Jolla, CA, USA). Protein synthesis was induced for $5 \mathrm{~h}$ at $37^{\circ} \mathrm{C}$ with $1 \mathrm{mM}$ isopropyl $\beta$-D-1thiogalactopyranoside and the recombinant proteins were purified from the inclusion body fraction after solubilisation in $6 \mathrm{M}$ guanidinium hydrochloride, $100 \mathrm{mM} \mathrm{NaH} \mathrm{PO}_{4}, 10 \mathrm{mM}$ Tris ( $\mathrm{pH} 8$ ) using a Ni-NTA affinity matrix (Qiagen). The proteins were adsorbed, the column washed with washing buffer $(8 \mathrm{M}$ urea, $100 \mathrm{mM} \mathrm{NaH} \mathrm{PO}_{4}, 10 \mathrm{mM}$ Tris- $\mathrm{HCl}(\mathrm{pH}$ 5.9)) and the proteins were eluted with the same buffer adjusted with $\mathrm{HCl}$ to
pH 3.5. Protein preparations were dialysed against buffers with decreasing urea concentration and finally against double distilled $\mathrm{H}_{2} \mathrm{O}$. Protein purity and concentration were checked by SDS-PAGE followed by Coomassie blue staining [34].

Recombinant 89VP1 fragments comprising amino acids 1-100, 101-200 and 201-293 were expressed as fusions to maltose binding protein using plasmid pMalC4X in E. coli BL21 (DE3) and purified by amylose affinity chromatography (New England Biolabs, Ipswich, MA, USA).

\section{Synthetic peptides and peptide conjugates}

HRV14-derived peptides (PVP1A, PVP1B and PVP3A) were synthesised on the Applied Biosystems (Foster City, CA, USA) peptide synthesiser Model 433A using Fmoc (9-fluorenylmethoxy-carbonyl) strategy with HBTU (2-(1H-Benzotriazol-1yl)1,1,3,3 tetramethyluronium hexafluorophosphate) activation. The following peptides were purified to $>90 \%$ purity by preparative high-performance liquid chromatography (piChem, Graz, Austria) and their identity was verified by mass spectrometry: PVP1A: VVQAMYVPPGAPNPKEC amino acids 147-162 of VP1 [18]; PVP1B: CRAPRALPYTSIGRTNYPKNTEPVIKKRKGDIKSY amino acids 256-289 of VP1 (i.e. Cterminal residues); PVP3A: KLILAYTPPGARGPQDC amino acids 126-141 of VP3 [18]. a)

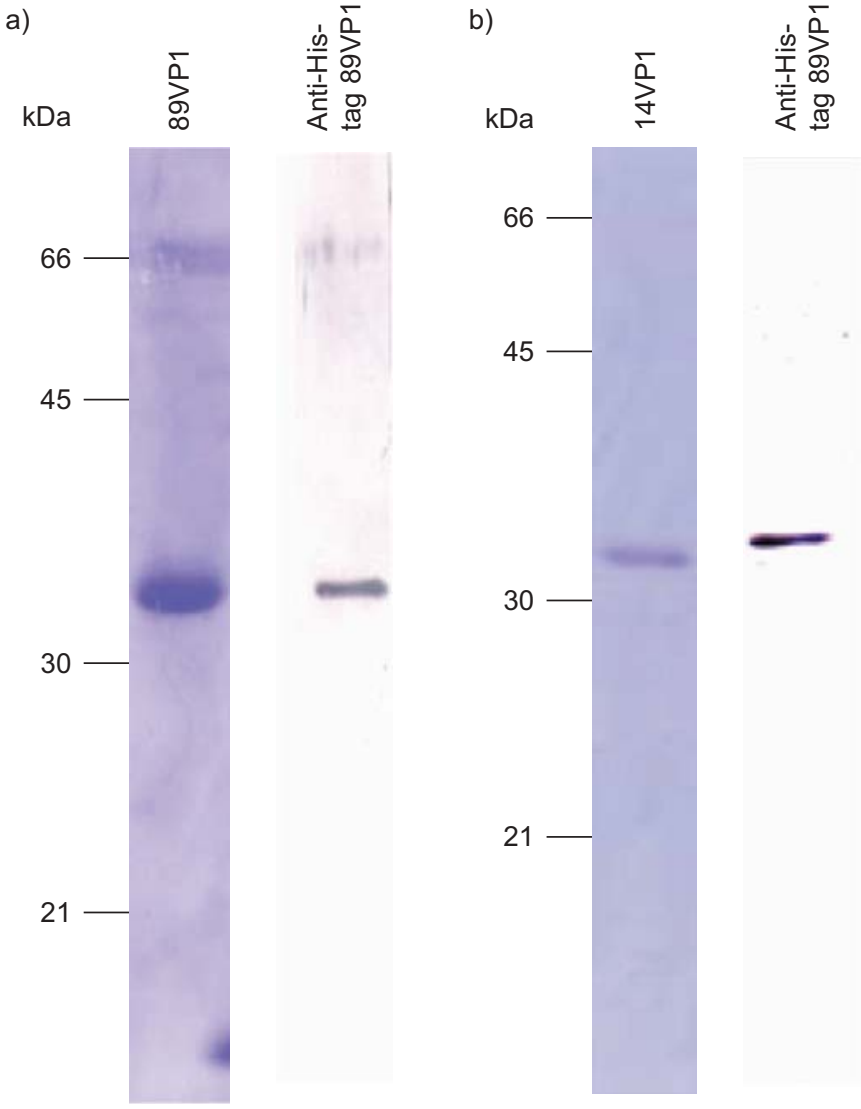

FIGURE 1. Purification of recombinant VP1 proteins. a) 89VP1 and b) 14VP1 were stained with Coomassie blue after SDS-PAGE (left lanes) and with an anti-His6 antibody (right lanes) after blotting on nitrocellulose. Positions of molecular weight markers run in parallel are indicated. 

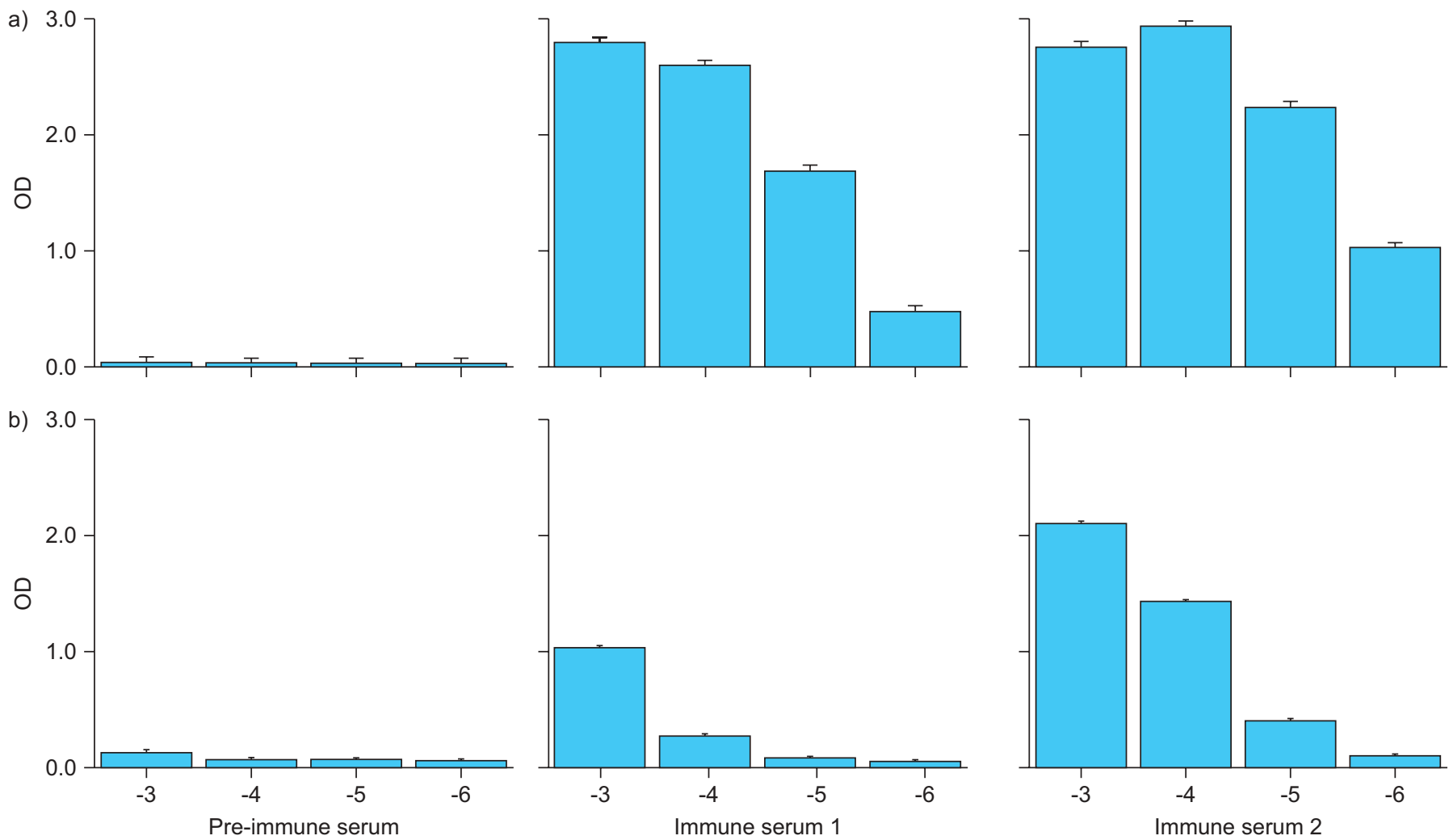

Serum dilution log

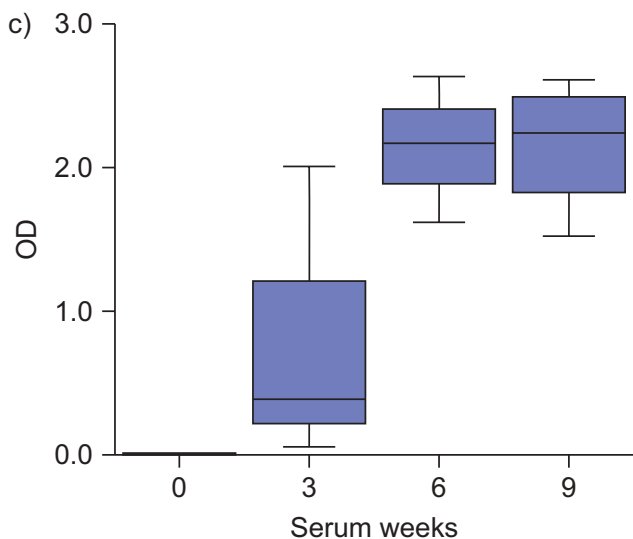

Purified peptides were coupled to keyhole limpit haemocyanin (KLH) using the Imject Maleimide Activated Immunogen Conjugation Kit (Pierce, Rockfort, IL, USA) according to the manufacturer's instructions.

\section{Immunisation of mice and rabbits}

Rabbit antibodies against 14VP1, 89VP1, PVP1A, PVP1B and PVP3A, respectively, were obtained by immunising rabbits (Charles River, Kisslegg, Germany). Groups of five mice were also immunised subcutaneously with $5 \mu \mathrm{g}$ of $89 \mathrm{VP} 1$ adsorbed to alum in 3-week intervals and bled from the tail veins [35]. Animals were maintained in the animal care unit of the Dept of Pathophysiology (Medical University of Vienna, Vienna) according to the local guidelines for animal care [35].
FIGURE 2. VP1-specific immune responses of immunised rabbits and mice. a) 89VP1- and b) 14VP1-specific immunoglobulin (Ig)G responses in rabbits. Rabbits were immunised with 89VP1 or 14VP1. Serum samples were taken on the day of the first immunisation (pre-immune serum) and after the second and third injection in 34-week intervals (immune serum 1 and immune serum 2). Dilutions of the sera (rabbit anti-89VP1 and rabbit anti-14VP1) are presented $\left(10^{-3}-10^{-6}\right.$ indicated as log). IgG reactivities toward the immunogens (89VP1 and 14VP1) were determined by ELISA and are depicted. c) A group of five mice were immunised with 89VP1. Serum samples were taken on the day of the first immunisation (0) and in 3-week intervals (3-9 weeks). IgG 1 reactivities are displayed for the group as a box plot where $50 \%$ of the values are within the boxes and nonoutliers between the bars. Lines within the boxes indicate the median values. Ig $G_{1}$ levels specific for 89VP1 were determined by ELISA. OD: optical density.

\section{ELISA experiments}

ELISA plates were coated with $5 \mu \mathrm{g} \cdot \mathrm{mL}^{-1} 89 \mathrm{VP} 1,14 \mathrm{VP} 1$ and recombinant fragments of $89 \mathrm{VP} 1$, respectively [36]. The mouse sera were diluted $1: 500$ and the rabbit sera $1: 10^{3}-1: 10^{6}$. Antigen-specific immunoglobulin ( $\mathrm{Ig}) \mathrm{G}_{1}$ mouse antibodies were detected with 1:1,000 diluted alkaline phosphatasecoupled mouse monoclonal anti-mouse $\operatorname{IgG}_{1}$ antibodies (BD Biosciences Pharmingen, San Diego, CA, USA). The reactivity of the rabbit anti-VP1 and rabbit anti-peptide antisera with the VP1 proteins was tested on one ELISA plate to allow a comparison of the titres. Antigen-specific rabbit IgG antibodies were developed with a 1:2,000 dilution of donkey anti-rabbit IgG peroxidase-coupled antibodies (Amersham Biosciences, Europe, Freiburg, Germany). Binding was quantified at $405 \mathrm{~nm}$ and $490 \mathrm{~nm}$ for rabbit antibodies and at $405 \mathrm{~nm}$ and 
$450 \mathrm{~nm}$ for mice antibodies in an ELISA reader (Dynatech, Denkendorf, Germany) [35, 37].

\section{Reactivity of anti-VP1 antibodies in Western blots}

Cell culture supernatants from HRV14 infected HeLa cells were centrifuged in a bench centrifuge $(37,500 \times g, 10 \mathrm{~min}$, $20^{\circ} \mathrm{C}$ ) to remove cell debris. A solution $(0.5 \mathrm{~mL})$ of $40 \%$ volume/volume polyethylene glycol 6000, 2.4\% weight/ volume $\mathrm{NaCl}$ ) was added to $2 \mathrm{~mL}$ of the virus-containing supernatant, incubated at $4{ }^{\circ} \mathrm{C}$ overnight and centrifuged at $5,750 \times g$ for $45 \mathrm{~min}$ in a bench centrifuge at room temperature. The pellet was resuspended in $100 \mu \mathrm{L}$ PBS and solubilised by adding $50 \mu \mathrm{L}$ SDS sample buffer. $10 \mu \mathrm{L}$ of this HRV14 protein extract and $0.5 \mu \mathrm{g}$ purified $14 \mathrm{VP} 1$ were separated in parallel by $12 \%$ SDS-PAGE and blotted onto nitrocellulose membranes $[34,38]$. Identically prepared blots were incubated with 1:500 dilutions of rabbit anti-14VP1 antibodies or the corresponding pre-immune Ig. Bound antibodies were detected with ${ }^{125} \mathrm{I}-$ labelled donkey anti-rabbit IgG and visualised by autoradiography [35, 37].

For immunogold electron microscopy, $4.2 \mu \mathrm{L}$ aliquots of the resuspended viral precipitate were pipetted onto carboncoated, plasma-cleaned copper grids and air-dried. After $5 \mathrm{~min}$, any remaining liquid was removed with a piece of filter paper. The grids were then incubated face down (moist chamber at room temperature) in the following buffers. PBS containing $1 \%(\mathrm{w} / \mathrm{v})$ bovine serum albumin (BSA) at $\mathrm{pH} 7.4$ and then $50 \mathrm{mM}$ Tris buffer containing 1\% (w/v) BSA at $\mathrm{pH}$ 8.2; followed by: 1) 5\% (w/v) BSA, $5 \mathrm{~min}$; 2) protein G-purified anti-VP1 Ig or pre-immune Ig adjusted to A280 0.6, 45 min; 3) six times PBS buffer, $5 \mathrm{~s}$ each; 4) six times $50 \mathrm{mM}$ Tris buffer, $5 \mathrm{~s}$ each; 5) goat anti-rabbit Ig coupled to colloidal gold particles with a diameter of $10 \mathrm{~nm}$ (Plano, Wetzlar, Germany), diluted 1:20 in $50 \mathrm{mM}$ Tris buffer, $30 \mathrm{~min}$; 6) six times $50 \mathrm{mM}$ Tris buffer, $5 \mathrm{~s}$ each; and 7) six times distilled water, $5 \mathrm{~s}$ each.
The immunogold labelling was followed by negative staining with a saturated solution of uranyl acetate. After $1 \mathrm{~min}$, surplus negative stain was removed with a wet filter paper. The grids were then air-dried and viewed in a Philips EM 410 transmission electron microscope (FEI, Eindhoven, the Netherlands) equipped with a high resolution CCD camera (Toshiba Teli Corporation, Tokyo, Japan). Micrographs were taken at a magnification of $165,000 \times$ or $240,000 \times$.

\section{HRV neutralisation test}

Rhinovirus stocks and the HRV-sensitive "Ohio" strain of HeLa cells [39] were kindly provided from the Institute of Virology (Medical University of Vienna, Vienna). HeLa cells were seeded in 24-well plates and grown to $\sim 90 \%$ confluence as described [18]. In a first set of experiments, $300 \mu \mathrm{L}$ aliquots of HRV14 (100 TCID50 (50\% tissue culture infection dose)) in medium were incubated for $2 \mathrm{~h}$ at $37^{\circ} \mathrm{C}$ with $300 \mu \mathrm{L}$ of rabbit antisera (anti-14VP1, anti-PVP1A, anti-PVP1B or PVP3A) or the corresponding pre-immune sera (undiluted or diluted 1:21:32) and added to the cells. Minimum essential medium (MEM) Eagle medium (Invitrogen) containing 1\% fetal calf serum (FCS) and $40 \mathrm{mM} \mathrm{MgCl}$ was used as a diluent in the experiments. Plates were incubated at $34^{\circ} \mathrm{C}$ in a humidified $5 \%$ $\mathrm{CO}_{2}$ atmosphere and viable cells were stained with crystal violet after 3 days [18]. Cross-neutralisation tests were carried out in 96-well plates; HeLa cells were seeded in MEM containing $2 \% \mathrm{FCS}, 30 \mathrm{mM} \mathrm{MgCl}_{2}$, and $1 \mathrm{mM}$ glutamine (infection medium) and grown overnight at $37^{\circ} \mathrm{C}$ to $\sim 70 \%$ confluency. HRVs (100 TCID50 in $100 \mu \mathrm{L}$ infection medium) were mixed with $100 \mu \mathrm{L}$ of the respective undiluted antiserum and serial two-fold dilutions thereof in the same medium. After incubation for $3 \mathrm{~h}$ at $37^{\circ} \mathrm{C}$, the cells were overlaid with these solutions and incubation was continued at $34^{\circ} \mathrm{C}$ for 3 days. The medium was removed and cells were stained with crystal violet $(0.1 \%$ in water) for $10 \mathrm{~min}$. After washing with water, the plate was dried, stained cells were dissolved in

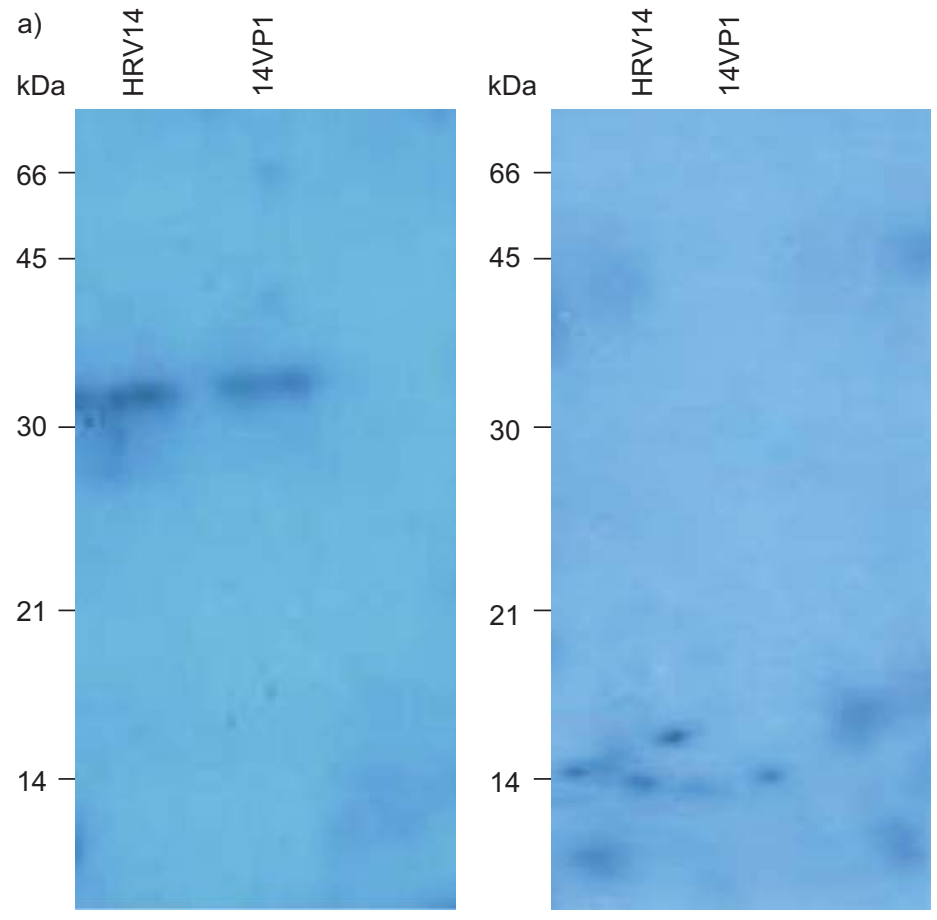

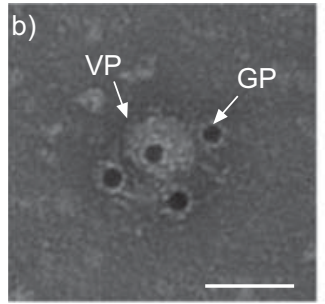

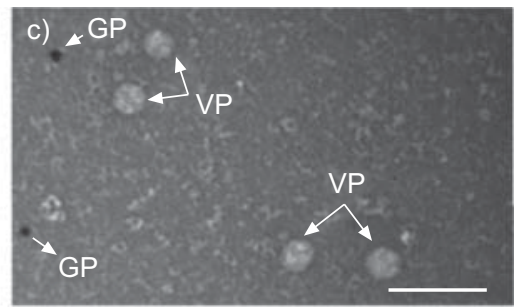

FIGURE 3. Anti-VP1 antibodies raised against recombinant VP1 react with rhinovirus-derived VP1 and whole virus. a) Nitrocellulose-blotted human rhinovirus (HRV)14 protein extract and recombinant 14VP1 were incubated with anti-14VP1 antibodies (left panel) and the corresponding pre-immune serum (right panel). Molecular weights in $\mathrm{kDa}$ are indicated. b, c) Electron micrographs of labelled virus preparations after negative staining. Immobilised HRV89 was incubated with anti-89VP1 immunoglobulin (lg)G antibodies (b) and the binding sites were visualised by a secondary lgG antibody probe coupled to colloidal gold particles with a diameter of $10 \mathrm{~nm}$. b) The micrograph gives a detail from a virus particle (VP) connected with four gold particles (GP). c) The micrograph shows the control preparation using the pre-immune lg. Scale bars b) $50 \mathrm{~nm}$ and c) $100 \mathrm{~nm}$. 
$30 \mu \mathrm{L} 1 \%$ SDS under shaking for $1 \mathrm{~h}$ and cell protection was quantified as A560 in a plate reader. The identity of all HRVs used was repeatedly confirmed by neutralisation with the respective type-specific quinea pig antisera from ATCC (Manassas, VA, USA).

\section{RESULTS}

\section{Expression and purification of recombinant VP1 proteins} from HRV89 and HRV14

Recombinant VP1 of HRV89 (89VP1; fig. 1a) and HRV14 (14VP1; fig. 1b) were expressed in E. coli with a His ${ }_{6}$-tag at their C-termini and purified from solubilised inclusion bodies by single step nickel affinity chromatography. SDS-PAGE followed by Coomassie blue staining revealed the purified protein bands at $\sim 34 \mathrm{kDa}$. Both the recombinant proteins 89VP1 and 14VP1 reacted specifically with the anti-His-tag antibody due to their C-terminal hexa-histidine tag (fig. 1).

\section{VP1 and 14VP1 induce a VP1-specific immune response in animals}

Immunisation of rabbits with recombinant 89VP1 and 14VP1 induced VP1-specific IgG responses (fig. 2a and b). The immune response to $89 \mathrm{VP} 1$ was stronger than that to $14 \mathrm{VP} 1$ with a strong signal detected up to a serum dilution of $10^{-5}$ after the second immunisation and up to a dilution of $10^{-6}$ after the third immunisation (fig. 2a). The 14VP1-specific IgG response was detectable up to a serum dilution of $10^{-3}$ after the second immunisation and up to a $10^{-4}$ dilution after the third immunisation (fig. 2b). VP1-specific antibody responses were also obtained in mice immunised with alum-adsorbed VP1 proteins. $\operatorname{IgG}_{1}$ antibodies specific for $89 \mathrm{VP} 1$ were detected after the first immunisation and increased until the second and third immunisation (fig. 2c).

\section{Reactivity of antibodies raised against recombinant VP1 proteins toward virus-derived VP1 and entire virions}

The reactivity of antibodies induced by immunisation with recombinant VP1 proteins with natural, virus-derived VP1 and whole virus was studied by immunoblotting and electron microscopy, respectively. As a representative example, binding of rabbit anti-14VP1 antibodies and lack of binding of preimmune Ig to nitrocellulose-blotted HRV14 proteins and $14 \mathrm{VP1}$ is shown in figure 3a. Antibodies raised against recombinant $14 \mathrm{VP} 1$, but not the pre-immune $\mathrm{Ig}$, reacted with natural and recombinant 14VP1 (band at $\sim 34 \mathrm{kDa}$ ) (fig. 3a). Specific binding of anti-89VP1 antibodies to HRV89 was visualised using the immunogold electron microscopy method. When immobilised virions were exposed to anti-89VP1 antibodies and gold-conjugated secondary antibodies $\sim 10 \%$ of the virus particles appeared coated with one and up to five colloidal gold particles (fig. 3b). No viral particles were stained in the control preparations with the pre-immune Ig (fig. 3c); few gold particles were present but not associated with virus particles (fig. $3 b$ and c).
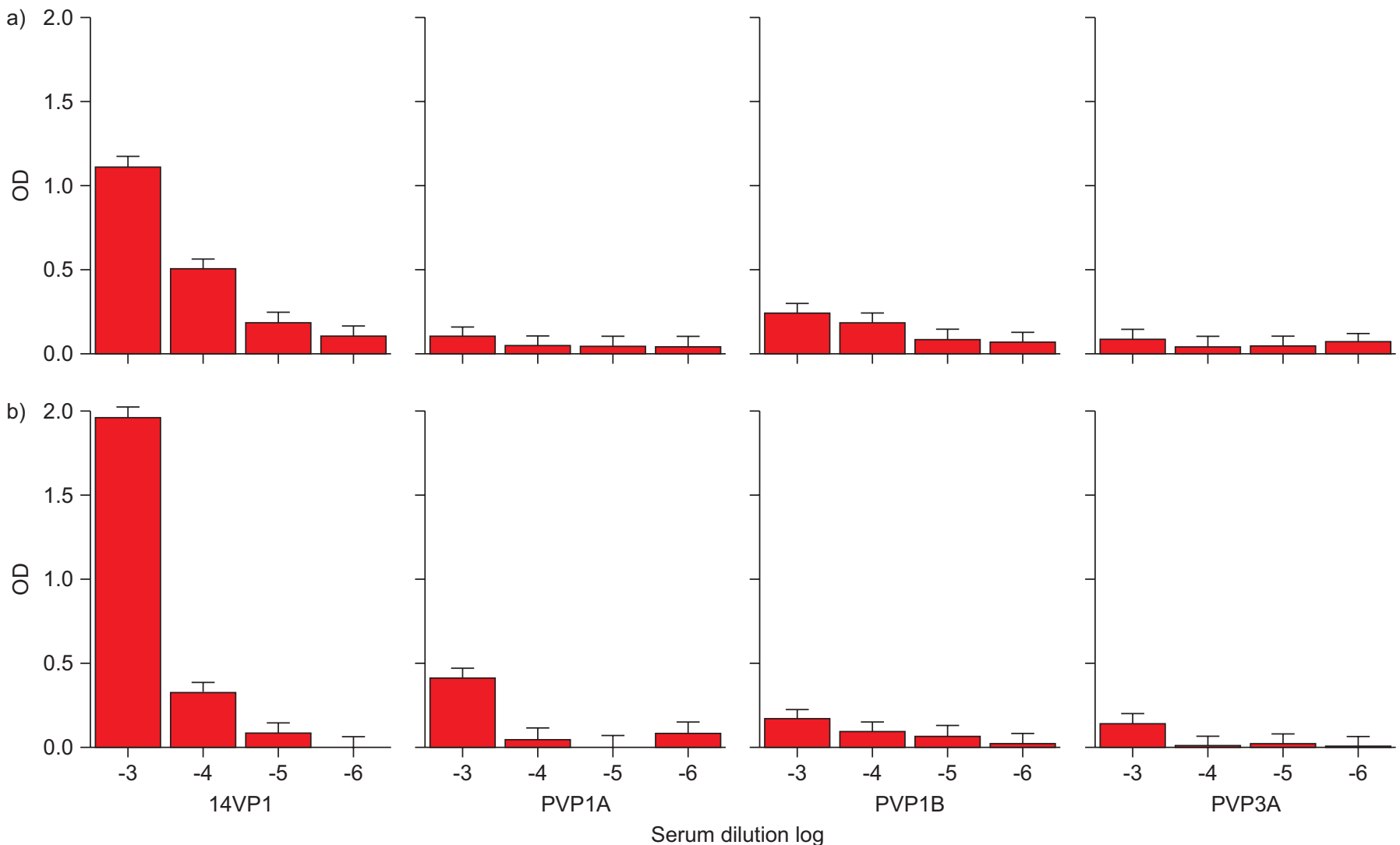

FIGURE 4. Reactivity of rabbit antisera raised against recombinant 14VP1 protein or 14VP1-derived peptides. Rabbits were immunised with recombinant 14VP1, PVP1A PVP1B or PVP3A and sera exposed to a) $14 \mathrm{VP1}$ or b) 89VP1. The dilutions of the sera are displayed $\left(10^{-3}-10^{-6}\right.$ indicated as log). Immunoglobulin (Ig)G levels specific for $14 \mathrm{VP1}$ and 89VP1 correspond to the optical density (OD) values. 

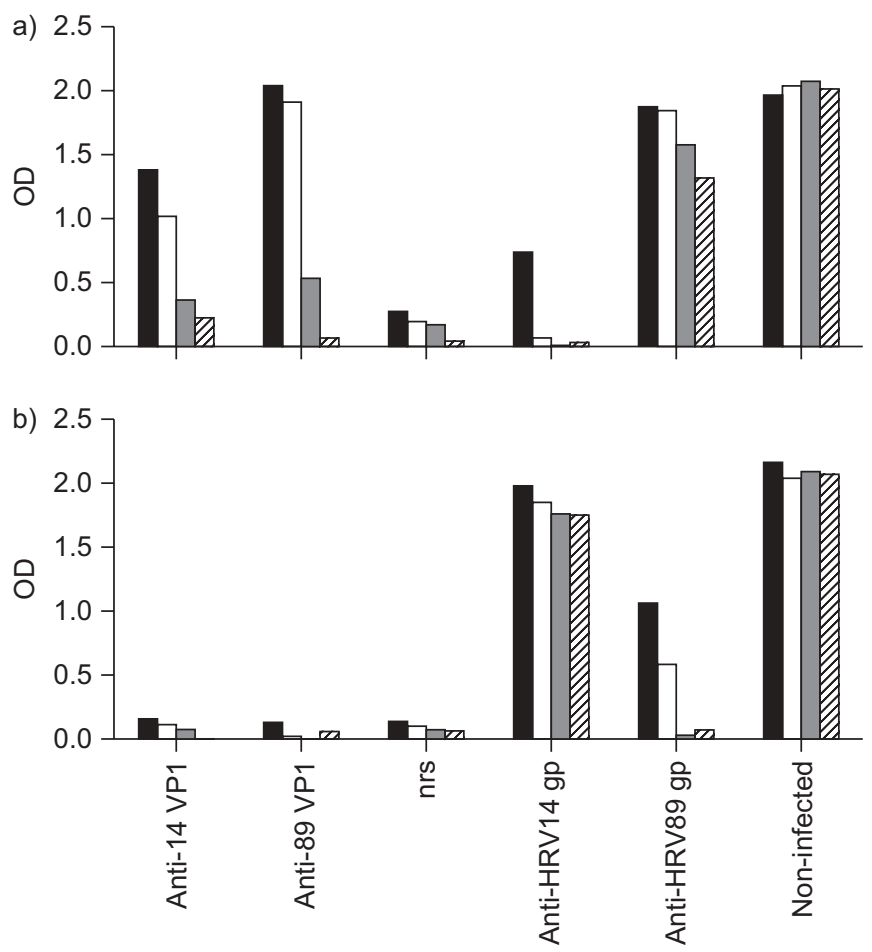

FIGURE 5. Neutralisation of a) human rhinovirus (HRV)89 and b) HRV14 by anti-14VP1 and anti-89VP1 antibodies. HRV14 and HRV89 at 100 TCID50 (50\% tissue culture infection dose) were pre-incubated with serial two-fold dilutions of the

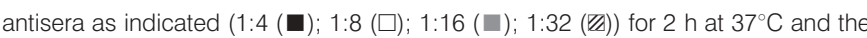
mixture was added to subconfluent HeLa cells in 24-well plates. After 3 days at $34^{\circ} \mathrm{C}$ remaining cells were stained with crystal violet, washed, the stain was dissolved and A560 was determined. Normal rabbit serum (nrs), type-specific quinea pig antisera (gp) from ATCC (Manassas, VA, USA) and noninfected cells were used as controls. OD: optical density

\section{Immunisation of rabbits with recombinant 14VP1 yields higher 14VP1- and 89VP1-specific antibody titres than immunisation with KLH-coupled HRV14-derived peptides}

Antisera were raised against KLH-coupled peptides which have been previously described as possible vaccine candidates [18]. The anti-peptide antisera contained high titres of peptidespecific antibodies (PVP1A:10 ${ }^{-3}$; PVP1B: $10^{-5}$; PVP3A: $10^{-5}$; data not shown). However, in comparison with antisera raised against recombinant 14VP1, they reacted only weakly with the 14VP1 protein and showed weak cross-reactivity with 89VP1 (fig. 4). Most remarkably, antiserum obtained upon immunisation with recombinant $14 \mathrm{VP} 1$ showed a comparable reactivity with 14VP1 and 89VP1. This antiserum reacted with VP1 of both viral serotypes at least 10-fold more strongly than the peptide antisera (fig. 4).

\section{VP1-specific antibodies inhibit HRV infection of HeLa cells better than peptide-specific antibodies}

Next, we investigated whether rabbit IgG antibodies raised against the two recombinant proteins (14VP1 and 89VP1) inhibit HRV infection of HeLa cells. As seen in figure 5, HRV89 infectivity was strongly neutralised by both anti-14VP1 and anti-89VP1 rabbit IgG antibodies in a dose-dependent manner up to a 1:32 dilution. However, the antiserum against VP1 of HRV14 only weakly protected against infection by HRV14.

\begin{tabular}{|c|c|c|c|c|c|c|c|}
\hline \multirow[t]{2}{*}{ TABLE } & \multicolumn{7}{|c|}{$\begin{array}{l}\text { Neutralisation of viral infectivity by antibodies } \\
\text { raised against 14VP1 and human rhinovirus } \\
\text { (HRV)14-derived peptides }\end{array}$} \\
\hline & Undiluted & $1: 2$ & $1: 4$ & $1: 8$ & $1: 16$ & $1: 32$ & $1: 64$ \\
\hline$\alpha$ 14VP1 & +++ & +++ & ++ & ++ & + & + & - \\
\hline$\alpha$ PVP1A & +++ & +++ & + & + & $+/-$ & $+/-$ & - \\
\hline$\alpha$ PVP1B & +++ & +++ & + & + & $+/-$ & $+/-$ & - \\
\hline$\alpha$ PVP3A & +++ & +++ & + & $+/-$ & $+/-$ & $+/-$ & - \\
\hline \multicolumn{8}{|c|}{$\begin{array}{l}\text { Serial two-fold dilutions of anti }(\alpha) \text {-14VP1, anti-PVP1A, anti-PVP1B or anti-PVP3A } \\
\text { antibodies (undiluted or diluted 1:2-1:32) were pre-incubated with } 100 \text { TCID50 } \\
\text { ( } 50 \% \text { tissue culture infection dose) HRV14 and added to HeLa cells in 96-well } \\
\text { plates. The respective cytopathic effects (CPE) observed are indicated: +++: } \\
\text { complete neutralisation; ++: minimal CPE; +: partial CPE; +/-: almost complete } \\
\text { CPE; -: complete CPE. }\end{array}$} \\
\hline
\end{tabular}

Antibodies from nonimmunised rabbits failed to protect (compared with noninfected cells used as a control). We also compared the ability of antibodies raised against complete 14VP1 with antibodies raised against 14VP1-derived peptides for protection of the cells against viral infection. Serial dilutions (undiluted or diluted 1:2-1:32) of anti-14VP1, -PVP1A, -PVP1B and -PVP3A antisera, respectively, were pre-incubated with HRV14 and these mixtures were added to HeLa cells grown in 96-well plates. All three anti-peptide antisera were comparable with respect to their ability to inhibit infection. A clear reduction of cytopathic effects (CPE) was seen at a dilution of 1:8 with antiPVP1A and anti-PVP1B and at a dilution of 1:4 with antiPVP3A. A similar degree of cell protection (i.e. only partial cytopathic effect) was obtained with the anti-14VP1 antiserum up to dilution of 1:32. This suggests that the latter antiserum was more potent in inhibiting viral infection (table 1).

\section{Antibodies raised against recombinant VP1 proteins show cross-protection against distantly related HRV strains}

Figure 6a shows the evolutionary relationship of the rhinovirus types used for the cross-protection experiments. They were selected to belong to different species and different receptor groups: HRV89 is a major group genus A; HRV3, HRV14, HRV37 and HRV72 are major group genus B; HRV18 and 54 are K-types (i.e. major group HRVs possessing a lysine in the HI loop of VP1) [40] and HRV1A, HRV29 and 44 are minor group genus $\mathrm{A}$. Both the anti-89VP1 and anti-14VP1 antibodies inhibited infection of HeLa cells by half of these HRV serotypes in a concentration-dependent manner independent of their evolutionary relationship (fig. $6 \mathrm{~b}$ and c). Interestingly, anti-14VP1 antibodies inhibited HRV89 infection more strongly than anti-89VP1 antibodies, whereas anti-89VP1 antibodies only weakly inhibited infection by HRV14 (fig. 6b and c). Remarkably, both antisera neutralised HRV44 more strongly than all other strains and showed extensive crossreactivity with weakly related $\mathrm{HRVs}$ (compare to fig. 6a). We tentatively explain this latter fact by VP1 from the different HRV strains possessing highly conserved sequence stretches that are most probably recognised by the antisera. In this context, it is noteworthy that the anti-VP1 antisera obtained by immunisation with VP1 from HRV14 and HRV89 differentially 
a)

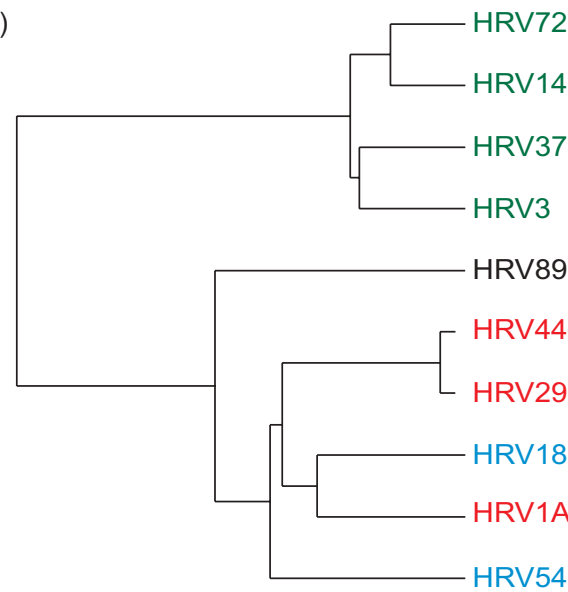

b) 2.5

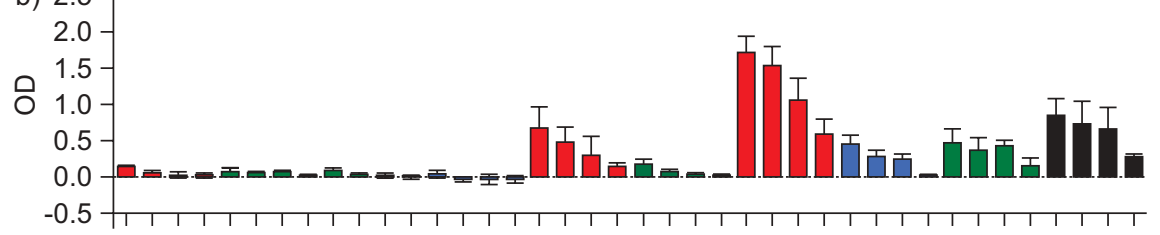

c) 2.5

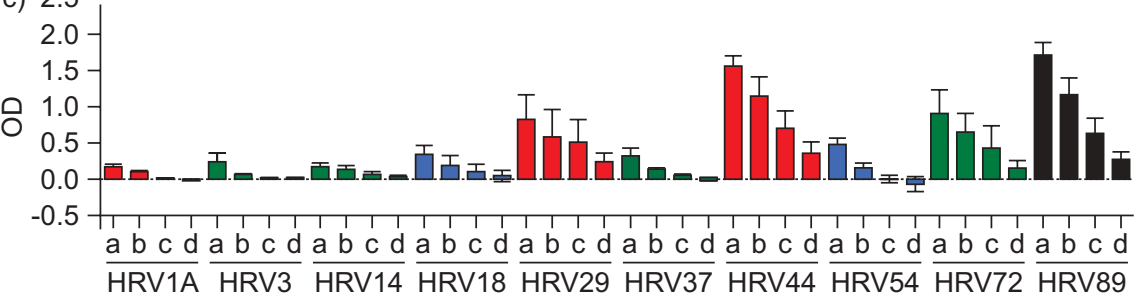

d)

HRV_89 NPVENYIDSVLNEVLVVPNIQPSTSVSSHAAPALDAAETGHTSSVQPEDMIETRYVITDQTRDETSIESFLGRSGCIAMIEFNTSSD-KTEHDKIGKGFK 99 HRV_37 GLGDELEEV. .EKTKQTLASIS.GPKH.QSV.T.T.N. . . A.MPTN.S.N. . . TTYMHENGS..D......AA..H.T.IENKNSTG.VNH.SD.L.N 1OO

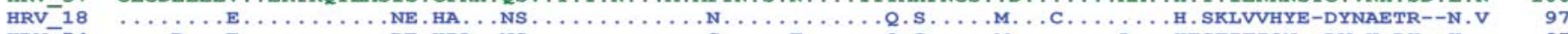

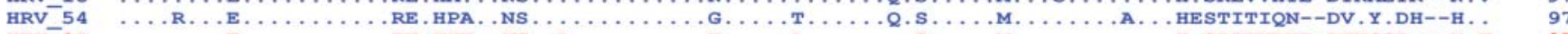

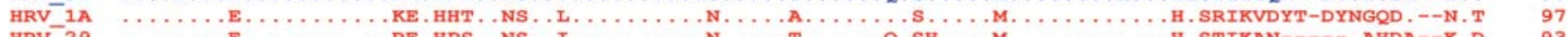

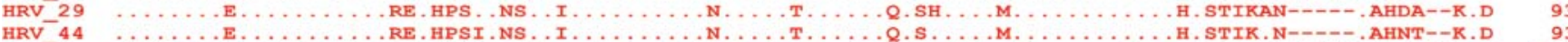

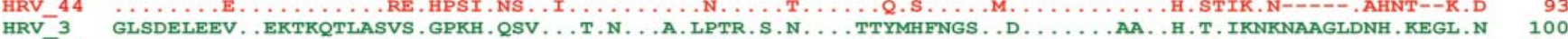
HRV_14 GLGDELEEV. . EKTKQTVASIS.GPKH.QKV.I.T.N. . . .MP.L.S.S. . TTYMHFNGS..D... . . AA..H.T.IQNKDATGIDNH.EA.L.N 1OO HRV_72 GLNDELEEV. EKTKQTLASIS.GPKY.QSV.T.T.N...A.MPTL.S.N. . TTYMHFNGS..D.C. . . AA..H.T.IENKNPNGISNH.AE.L.N 100

HRV_89 TWKVSLQEMAQIRRKYELFTYTRFDSEITIVTAAAA--QGNDSGHIVLQFMYVPPGAPVPEKRDDYTWQSGTNASVFWQEGQPYPRFTIPFMSIASAYYMFY 199

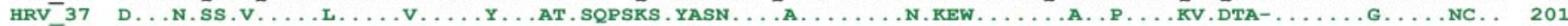

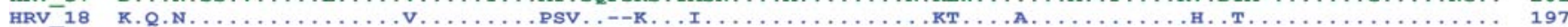
HRV 54 K D HRV IA K.

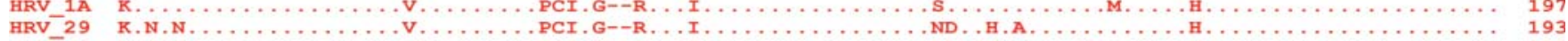

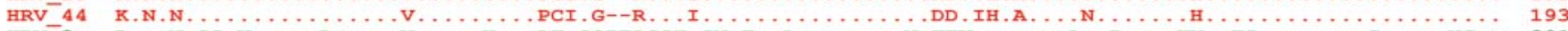

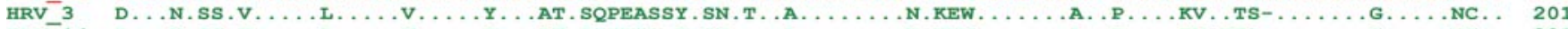

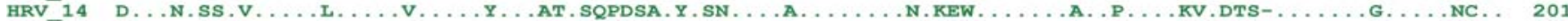

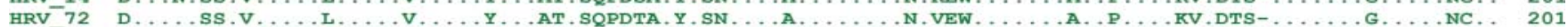

HRV_89 DGYDGDSAASKYGSVVTNDMGTICVRIVTSNQKHDLNIVCRIYHKAKHIKAWCPRPPRAVAYQHTHSTNYIPSNGEATTQIKTRP-DVFTVTNV 292

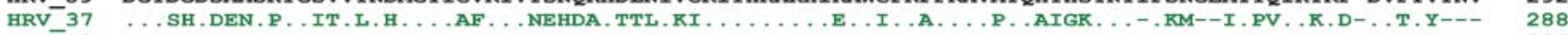
HRV_18 …

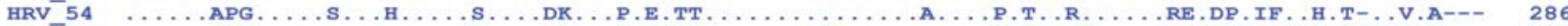

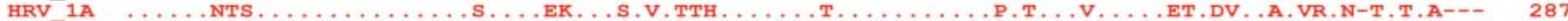

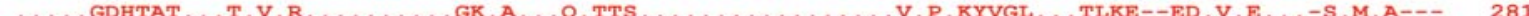

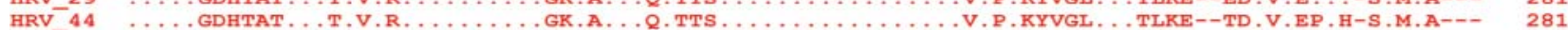

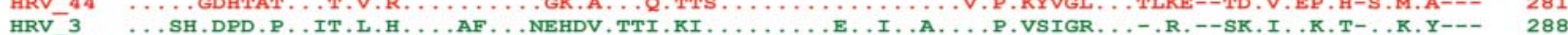

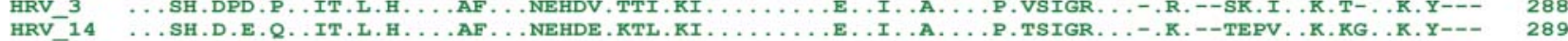

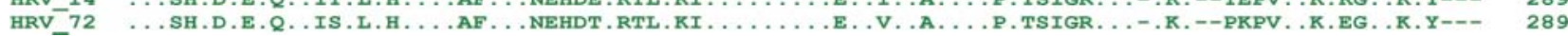

FIGURE 6. a) Phylogenetic tree of the VP1 sequences of the human rhinoviruses (HRVs) investigated. VP1 sequences were retrieved from the data bank and their similarity was analysed with ClustalW. Minor group genus A (red); K-type (major group) genus A (blue); major group genus A (black); and major group genus B (green). b, c) Inhibition of HRV infections by the respective VP1-specific antibodies, b) anti-89VP1 and c) anti-14VP1. HRVs at 100 TCID50 (50\% tissue culture infection dose) were preincubated with two-fold serial dilutions of the respective antisera at $1: 2$ (a); $1: 4$ (b); $1: 8$ (c) and 1:16 (d) for $3 \mathrm{~h}$ at $37^{\circ} \mathrm{C}$ and the mixtures were applied to subconfluent HeLa cells in 96-well plates. After incubation for 3 days at $34^{\circ} \mathrm{C}$, cells were stained with crystal violet, washed, the stain was dissolved and A560 was read. Mean \pm SE of four independent experiments is shown. d) Alignment of amino acid sequences of VP1 from the HRVs studied in this report. Dots represent identity.

reacted with recombinant fragments of $89 \mathrm{VP} 1$ spanning amino acids 1-100, 101-200 and 201-293 (fig. 7). Thus, it appears that this latter antiserum contains IgGs reacting with many more epitopes than the antiserum raised against 14VP1.

\section{DISCUSSION}

A vaccine protecting against rhinovirus infections may be useful to prevent, or at least ameliorate, rhinovirus-induced exacerbations of asthma and COPD. We have selected the HRV-derived VP1 capsid protein as a potential vaccine antigen for several reasons. The work of ROsSMANN et al. [17] elucidating the crystal structure of HRV14 demonstrates that VP1 is critically involved in HRV binding to its receptor on human epithelial cells. It was found that five copies of VP1 form a depression, called canyon and that the ICAM-1 receptor binds into the central part of this canyon [17, 41]. Furthermore, studies of spontaneous mutations in the viral coat led to the identification of four neutralising immunogenic sites on the surface of HRV14. Additional investigations revealed that antibodies to two of the four antigenic sites which are located on the VP1 protein blocked cellular attachment [42, 43]. MCCRAY and WERNER [18] showed that purified antibodies raised against peptides derived from the HRV14 capsid proteins VP1 and VP3 not only inhibited infection in tissue culture, but also cross-protected against $\sim 60 \%$ of 48 rhinovirus strains tested, whereas almost no other serotypes were neutralised by a whole anti-HRV14 antiserum. A more recent work by KATPALLY et al. [44] demonstrates that antibodies against synthetic peptides corresponding to the N-terminus of VP4 and VP1 from HRV14 are capable of neutralising viral 


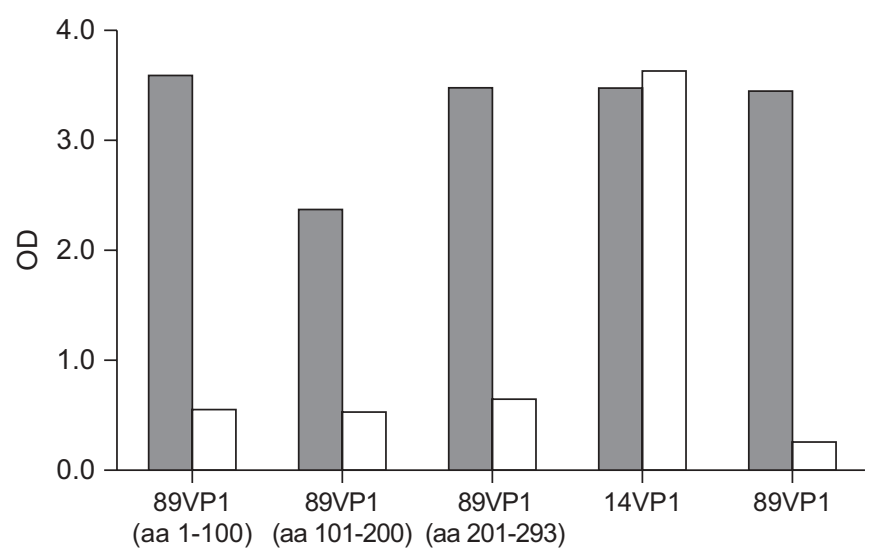

FIGURE 7. Reactivity of rabbit anti-89VP1 ( $\square$ ) and anti-14VP1 ( $\square$ ) antibodies with 14VP1, 89VP1 and three recombinant 89VP1 fragments. Rabbit sera were diluted 1:5,000 and A560 corresponding to bound immunoglobulin $\mathrm{G}$ antibodies is shown. OD: optical density; aa: amino acid.

infectivity. However, viral neutralisation using anti-VP4 antiserum was assessed for only two other serotypes, HRV16 and HRV29, and no significant neutralisation was found for the VP1 antiserum [44].

In the present study, we expressed the entire VP1 proteins from HRV89 and HRV14, which belong to the phylogenetically distant species HRV-A and HRV-B, respectively. Using the ClustalW program for alignment (www.ebi.ac.uk/clustalw) only a $41 \%$ amino acid identity is found between $89 \mathrm{VP} 1$ and 14VP1. Recombinant $14 \mathrm{VP} 1$ and 89VP1 were purified via a Cterminal His-tag by nickel affinity chromatography in a single step procedure. Immunisation of mice and rabbits with recombinant $14 \mathrm{VP} 1$ as well as $89 \mathrm{VP} 1$ proteins led to the development of VP1-specific antibody responses recognising natural VP1 from the virus and even intact virus as demonstrated by immunogold electron microscopy.

The antibody responses obtained with the VP1 proteins were compared with those induced by HRV14 VP1- and VP3derived peptides which had been earlier described as vaccine candidates [18] and with those obtained with a peptide (PVP1B) located at the C-terminus of the VP1 protein, being part of the ICAM-1 attachment site in HRV14 [45]. We found that the anti-HRV14 VP1 antisera reacted more strongly with VP1 than the anti-peptide antisera and exhibited a higher neutralisation titre. The higher neutralisation capacity and the remarkably broad cross-neutralising effects of the antibodies raised against the entire proteins is most likely due to the recognition of several epitopes on VP1 leading to a higher avidity as compared to that of the peptide-specific antibodies. In summary, our results strongly suggest that vaccines based on complete VP1 proteins induce a polyclonal immune response against several segments of the protein which increases the probability of cross-reaction. This is without doubt advantageous over the previously suggested peptide vaccines that necessarily must be less cross-protecting because of containing a limited repertoire of epitopes.

We have shown that antibodies raised against the recombinant VP1 proteins from both strains, HRV14 and HRV89, inhibited the infection of cultured HeLa cells by a variety of different rhinovirus strains belonging to the major and minor group. It is particularly notable that both anti-sera were more efficacious in neutralising HRV44 than the cognate serotype corresponding to the immunising antigen. This is corroborated by stronger binding of 89VP1 antibodies to VP1 of HRV44 as compared to VP1 of HRV2, 14 and 89 in Western blots (data not shown). Similar results were also obtained by MCCRAY and WERNER [18] who found that anti-HRV14 peptide antisera neutralised other strains better than HRV14. Along the same lines, KATPALLY et al. [44] also reported that anti-VP4 antibodies against VP4-derived peptides neutralise HRV16 much better than HRV14. These findings suggest either that a varying exposure of capsid proteins or protein regions in different strains may influence neutralisation or that different epitopes are important for the neutralisation of different HRVs [46]. Most likely, the cross-neutralisation capacity of a rhinovirus vaccine might be increased by identifying and combining such epitopes, following the rationale of our work. The absence of a suitable animal model makes in vivo testing of candidate vaccines for protection against rhinovirus infections difficult. In a pilot study, one person was vaccinated with recombinant 89VP1 and shown to produce VP1-specific IgG and IgA responses (data not shown).

Major advantages of a vaccine based on recombinant rhinovirus capsid proteins are that the vaccine antigens can be easily produced under controlled conditions by large scale recombinant expression in foreign hosts, such as E. coli at reasonable costs. A broadly cross-protective HRV vaccine may be especially useful for the vaccination of patients suffering from rhinovirus-induced respiratory diseases and may thus reduce asthma and COPD exacerbations.

\section{SUPPORT STATEMENT}

This study was supported by grant L214-B13, P18693-B09 and the DK program "Inflammation and Immunity" of the Austrian Science Fund (FWF).

\section{STATEMENT OF INTEREST}

A statement of interest for R. Valenta can be found at www.erj. ersjournals.com/site/misc/statements.xhtml

\section{ACKNOWLEDGEMENTS}

We thank I. Gösler (MFPL, Dept of Med. Biochem, Medical University of Vienna, Vienna, Austria) for virus preparation and neutralisation tests.

\section{REFERENCES}

1 Holgate ST. Rhinoviruses in the pathogenesis of asthma: the bronchial epithelium as a major disease target. I Allergy Clin Immunol 2006; 118: 587-590.

2 Wos M, Sanak M, Soja J, et al. The presence of rhinovirus in lower airways of patients with bronchial asthma. Am J Respir Crit Care Med 2008; 177: 1082-1089.

3 Seemungal T, Harper-Owen R, Bhowmik A, et al. Respiratory viruses, symptoms, and inflammatory markers in acute exacerbations and stable chronic obstructive pulmonary disease. Am J Respir Crit Care Med 2001; 164: 1618-1623.

4 Rohde G, Wiethege A, Borg I, et al. Respiratory viruses in exacerbations of chronic obstructive pulmonary disease requiring hospitalisation: a case-control study. Thorax 2003; 58: 37-42. 
5 Wat D, Gelder C, Hibbitts S, et al. The role of respiratory viruses in cystic fibrosis. J Cyst Fibros 2008; 7: 320-328.

6 Abzug MJ, Beam AC, Gyorkos EA, et al. Viral pneumonia in the first month of life. Pediatr Infect Dis J 1990; 9: 881-885.

7 Nicholson KG, Kent J, Hammersley V, et al. Risk factors for lower respiratory complications of rhinovirus infections in elderly people living in the community: prospective cohort study. BMJ 1996; 313: 1119-1123.

8 Gerna G, Piralla A, Rovida F, et al. Correlation of rhinovirus load in the respiratory tract and clinical symptoms in hospitalized immunocompetent and immunocompromised patients. J Med Virol 2009; 81: 1498-1507.

9 Mackay IM. Human rhinoviruses: the cold wars resume. J Clin Virol 2008; 42: 297-320.

10 Palmenberg AC, Spiro D, Kuzmickas R, et al. Sequencing and analyses of all known human rhinovirus genomes reveal structure and evolution. Science 2009; 324: 55-59.

11 Ledford RM, Patel NR, Demenczuk TM, et al. VP1 sequencing of all human rhinovirus serotypes: insights into genus phylogeny and susceptibility to antiviral capsid-binding compounds. J Virol 2004; 78: 3663-3674.

12 Lau SK, Yip CC, Tsoi HW, et al. Clinical features and complete genome characterization of a distinct human rhinovirus (HRV) genetic cluster, probably representing a previously undetected HRV species, HRV-C, associated with acute respiratory illness in children. J Clin Microbiol 2007; 45: 3655-3664.

13 Lee WM, Kiesner C, Pappas T, et al. A diverse group of previously unrecognized human rhinoviruses are common causes of respiratory illnesses in infants. PLoS One 2007; 2: e966.

14 Greve JM, Davis G, Meyer AM, et al. The major human rhinovirus receptor is ICAM-1. Cell 1989; 56: 839-847.

15 Hofer F, Gruenberger M, Kowalski H, et al. Members of the low density lipoprotein receptor family mediate cell entry of a minorgroup common cold virus. Proc Natl Acad Sci USA 1994; 91: 1839-1842.

16 Couch RB. Rhinoviruses. In: Fields BN, Knipe DM, Mowley PM, et al., eds. Fields Virology. 3rd Edn. Philadelphia, LippincottRaven Publishers, 1996; pp. 713-734.

17 Rossmann MG, Arnold E, Erickson JW, et al. Structure of a human common cold virus and functional relationship to other picornaviruses. Nature 1985; 317: 145-153.

18 McCray J, Werner G. Different rhinovirus serotypes neutralized by antipeptide antibodies. Nature 1987; 329: 736-738.

19 Smith TJ. Antibody interactions with rhinovirus. Semler BL, Wimmer E, eds. In: Molecular Biology of Picornaviruses. Washington, ASM Press, 2002; pp. 39-49.

20 Hewat EA, Marlovits TC, Blaas D. Structure of a neutralizing antibody bound monovalently to human rhinovirus 2. J Virol 1998; 72: 4396-4402.

21 Che Z, Olson NH, Leippe D, et al. Antibody-mediated neutralization of human rhinovirus 14 explored by means of cryoelectron microscopy and X-ray crystallography of virus-Fab complexes. J Virol 1998; 72: 4610-4622.

22 Hadfield AT, Lee $\mathrm{W}$, Zhao R, et al. The refined structure of human rhinovirus 16 at $2.15 \AA$ resolution: implications for the viral life cycle. Structure 1997; 5: 427-441.

23 Verdaguer N, Blaas D, Fita I. Structure of human rhinovirus serotype 2 (HRV2). J Mol Biol 2000; 300: 1179-1194.

24 Nicholson KG, Kent J, Ireland DC. Respiratory viruses and exacerbations of asthma in adults. BMJ 1993; 307: 982-986.

25 Johnston SL, Pattemore PK, Sanderson G, et al. The relationship between upper respiratory infections and hospital admissions for asthma: a time-trend analysis. Am J Respir Crit Care Med 1996; 154: 654-660.
26 Jackson DJ, Gangnon RE, Evans MD, et al. Wheezing rhinovirus illnesses in early life predict asthma development in high-risk children. Am J Respir Crit Care Med 2008; 178: 667-672.

27 Sears MR. Epidemiology of asthma exacerbations. J Allergy Clin Immunol 2008; 122: 662-668.

28 Message SD, Laza-Stanca V, Mallia P, et al. Rhinovirus-induced lower respiratory illness is increased in asthma and related to virus load and Th1/2 cytokine and IL-10 production. Proc Natl Acad Sci USA 2008; 105: 13562-13567.

29 Douglas RG Jr, Couch RB. Attenuation of rhinovirus type 15 for humans. Nature 1969; 223: 213-214.

30 Francis MJ, Hastings GZ, Sangar DV, et al. A synthetic peptide which elicits neutralizing antibody against human rhinovirus type 2. J Gen Virol 1987; 68: 2687-2691.

31 Fang F, Yu M. Viral receptor blockage by multivalent recombinant antibody fusion proteins: inhibiting human rhinovirus (HRV) infection with CFY196. J Antimicrob Chemother 2004; 53: 23-25.

32 De Palma AM, Vliegen I, De Clercq E, et al. Selective inhibitors of picornavirus replication. Med Res Rev 2008; 28: 823-884.

33 Skern $\mathrm{T}$, Torgersen $\mathrm{H}$, Auer $\mathrm{H}$, et al. Human rhinovirus mutants resistant to low pH. Virology 1991; 183: 757-763.

34 Fling SP, Gregerson DS. Peptide and protein molecular weight determination by electrophoresis using a high-molarity tris buffer system without urea. Anal Biochem 1986; 155: 83-88.

35 Focke M, Mahler V, Ball $\mathrm{T}$, et al. Nonanaphylactic synthetic peptides derived from $B$ cell epitopes of the major grass pollen allergen, Phl p 1, for allergy vaccination. FASEB J 2001; 15: 2042-2044.

36 Niederberger V, Pauli G, Gronlund H, et al. Recombinant birch pollen allergens (rBet $\mathrm{v} 1$ and $\mathrm{rBet} v \mathrm{v}$ ) contain most of the $\operatorname{IgE}$ epitopes present in birch, alder, hornbeam, hazel, and oak pollen: a quantitative $\operatorname{IgE}$ inhibition study with sera from different populations. J Allergy Clin Immunol 1998; 102: 579-591.

37 Focke M, Linhart B, Hartl A, et al. Non-anaphylactic surfaceexposed peptides of the major birch pollen allergen, Bet $\mathrm{v} 1$, for preventive vaccination. Clin Exp Allergy 2004; 34: 1525-1533.

38 Towbin H, Staehelin T, Gordon J. Electrophoretic transfer of proteins from polyacrylamide gels to nitrocellulose sheets: procedure and some applications. Proc Natl Acad Sci USA 1979; 76: $4350-4354$.

39 Stott EJ, Tyrrell DA. Some improved techniques for the study of rhinoviruses using HeLa cells. Arch Gesamte Virusforsch 1968; 23: 236-244.

40 Vlasak M, Roivainen M, Reithmayer M, et al. The minor receptor group of human rhinovirus (HRV) includes HRV23 and HRV25, but the presence of a lysine in the VP1 HI loop is not sufficient for receptor binding. J Virol 2005; 79: 7389-7395.

41 Rossmann MG. The canyon hypothesis. Viral Immunol 1989; 2 143-161.

42 Verdaguer N, Fita I, Reithmayer M, et al. X-ray structure of a minor group human rhinovirus bound to a fragment of its cellular receptor protein. Nat Struct Mol Biol 2004; 11: 429-434.

43 Colonno RJ, Callahan PL, Leippe DM, et al. Inhibition of rhinovirus attachment by neutralizing monoclonal antibodies and their Fab fragments. J Virol 1989; 63: 36-42.

44 Katpally U, Fu TM, Freed DC, et al. Antibodies to the buried N terminus of rhinovirus VP4 exhibit cross-serotypic neutralization. J Virol 2009; 83: 7040-7048.

45 Kolatkar PR, Bella J, Olson NH, et al. Structural studies of two rhinovirus serotypes complexed with fragments of their cellular receptor. EMBO J 1999; 18: 6249-6259.

46 Lewis JK, Bothner B, Smith TJ, et al. Antiviral agent blocks breathing of the common cold virus. Proc Natl Acad Sci 1998; 95: 6774-6778. 